\title{
New genus-specific primers for the PCR identification of novel isolates of the genera Nocardiopsis and Saccharothrix
}

Centro de Investigación Básica, Merck Research Laboratories, Merck Sharp and Dohme de España SA, Josefa Valcárcel 38, E-28027 Madrid, Spain

\author{
Oscar Salazar, Ignacio González and Olga Genilloud \\ Author for correspondence: Olga Genilloud. Tel: +34 913210 568. Fax: +34 913210614 . \\ e-mail: olga_genilloud@merck.com
}

\begin{abstract}
The taxonomic position of the genera Saccharothrix and Nocardiopsis has evolved in recent years to accommodate an increasing number of actinomycete strains that cannot be clearly distinguished by morphological characters. More recently, the taxonomic reorganization of the genus Saccharothrix has determined the creation of new, related genera, increasing the complexity of the identification of this taxon. Nevertheless, today these genera can still only be identified by applying chemotaxonomic and molecular criteria, and no other tools are available for the rapid distinction of members of the two genera. Phylogenetic analysis based on 16S rDNA nucleotide sequences of reference strains has shown that both genera represent complete distinct lineages within the order Actinomycetales. Differences in the nucleotide sequences of the $16 \mathrm{~S}$ rDNAs of reference strains were used to design two pairs of genus-specific primers to identify novel members of the genera Nocardiopsis and Saccharothrix by PCR amplification. The genus specificity of these primers was validated with reference strains as well as with wild-type isolates that exhibited morphological characteristics common to both genera. The diversity and taxonomic position of the isolates identified with these tools is also discussed.
\end{abstract}

Keywords: Nocardiopsis, Saccharothrix, genus-specific primers, PCR, 16S rDNA sequences

\section{INTRODUCTION}

The composition of the genera Saccharothrix and Nocardiopsis has evolved in recent years to accommodate an increasing number of actinomycete strains that, although unrelated phylogenetically, cannot be clearly distinguished by morphological characters and, today, can still only be identified by chemotaxonomic and molecular criteria.

The genus Nocardiopsis was described by Meyer (1976) on the basis of the morphological characteristics and cell-wall type of the species Actinomadura dassonvillei. The genus is currently defined on the basis of chemotaxonomic markers including cell-wall chemotype IIIC

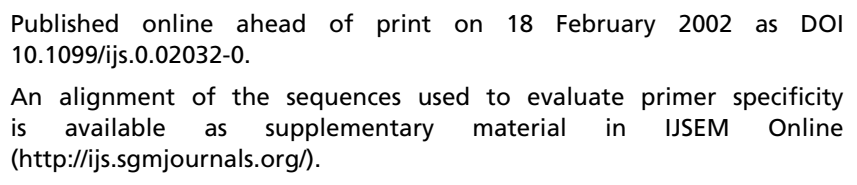

(Lechevalier et al., 1977), phospholipid type III (phosphatidylcholine and phosphatidylmethylethanolamine as diagnostic phospholipids) (Lechevalier et al., 1977), menaquinone MK-10 with variable degrees of saturation (Kroppenstedt, 1992) and fatty acid type 3d (Kroppenstedt, 1985). Other chemotaxonomic features include a lack of mycolic acids, the presence of muramic acid of the acetyl type and DNA $\mathrm{G}+\mathrm{C}$ contents between 64 and $71 \mathrm{~mol} \%$ (Labeda et al., 1984; Kroppenstedt, 1985, 1992; Poschner et al., 1985). On the basis of chemotaxonomic characteristics, Grund \& Kroppenstedt (1989) transferred five species of this genus (Nocardiopsis coeruleofusca, Nocardiopsis flava, Nocardiopsis longispora, Nocardiopsis mutabilis and Nocardiopsis syringae) to the genus Saccharothrix. The two invalid species 'Actinomyces alborubidus' and 'Streptomyces listeri' were later reclassified as members of Nocardiopsis on the basis of chemotaxonomic and numerical data (as Nocardiopsis alborubidus and Nocardiopsis listeri) (Grund \& Kroppenstedt, 1990). More recently, the strain Nocardiopsis sp. K-252 
$\left(=\mathrm{NRRL} 15532^{\mathrm{T}}\right)$ was transferred to the genus Nonomuraea as Nonomuraea longicatena sp. nov. on the basis of chemotaxonomic, morphological, DNADNA reassociation and $16 \mathrm{~S}$ rDNA sequence data (Chiba et al., 1999). The genus Nocardiopsis then contained seven validated species: Nocardiopsis dassonvillei (Meyer, 1976), Nocardiopsis alba, Nocardiopsis listeri (Grund \& Kroppenstedt, 1990), Nocardiopsis halophila (Al-Tai \& Ruan, 1994), Nocardiopsis lucentensis (Yassin et al., 1993), Nocardiopsis prasina and Nocardiopsis synnemataformans (Yassin et al., 1997). Recently, the genus has been amended by the addition of four newly described taxa, Nocardiopsis tropica, Nocardiopsis trehalosi and $N$. dassonvillei subsp. albirubida (Evtushenko et al., 2000) and Nocardiopsis kunsanensis (Chun et al., 2000). During revision of this work, four further species have been added: Nocardiopsis exhalans and Nocardiopsis umidischolae (Peltola et al., 2001), Nocardiopsis halotolerans (AlZarban et al., 2002) and Nocardiopsis compostus (Kämpfer et al., 2002). The results of 16S rDNA sequence analysis have shown that the genus Nocardiopsis is phylogenetically coherent and represents a distinct lineage within the order Actinomycetales, and the novel family Nocardiopsaceae was proposed for this genus (Rainey et al., 1996).

The genus Saccharothrix was first described to classify actinomycete isolates that were morphologically similar to Nocardiopsis, but were differentiated by chemotaxonomic markers (Labeda et al., 1984). The genus Saccharothrix is characterized by the presence of cellwall type III (meso-diaminopimelic acid), rhamnose and galactose as diagnostic whole-cell sugars, phospholipid type PII, the presence of MK-9 (Labeda et al., 1984) and fatty acid type $3 f$ (Kroppenstedt, 1985). The DNA $\mathrm{G}+\mathrm{C}$ contents of Saccharothrix species range from 70 to $76 \mathrm{~mol} \%$ (Labeda \& Lechevalier, 1989). On the basis of $16 \mathrm{~S}$ rDNA sequences, the genus was initially related to the family Pseudonocardiaceae (Warwick et al., 1994), but was later proposed to be included in the novel family Actinosynnemataceae with the genera Lentzea, Actinosynnema and Actinokineospora (Labeda \& Kroppenstedt, 2000). More recently, additional studies have clarified the phylogenetic heterogeneity of the genus Saccharothrix, resulting in the taxonomic reorganization of its species. The genus Saccharothrix comprises currently nine described species: Saccharothrix australiensis, Saccharothrix coeruleofusca, Saccharothrix coeruleoviolacea, Saccharothrix espanaensis, Saccharothrix longispora, Saccharothrix mutabilis, Saccharothrix syringae, Saccharothrix tangerinus and Saccharothrix texasensis (Labeda, 1986; Labeda \& Lyons, 1989). The strains Saccharothrix aerocolonigenes NRRL VB-3298 ${ }^{\mathrm{T}}$ and Saccharothrix flava NRRL B-16131 $1^{\mathrm{T}}$ have been transferred to the new genus Lechevalieria as Lechevalieria aerocolonigenes and Lechevalieria flava. The genus Lentzea has been revived, together with the species Lentzea albidocapillata, previously transferred to Saccharothrix (Lee et al., 2000). The species Saccharothrix violacea and Saccharothrix waywayandensis have been transferred to the revived genus Lentzea as Lentzea violacea and Lentzea waywayandensis, as well as the strain S. aerocolonigenes NRRL B-16137, now classified as Lentzea californiensis (Labeda et al., 2001). Finally, the genus Crossiella has been created to accommodate the species Saccharothrix cryophilis, more closely related phylogenetically to the genus Streptoalloteichus (Labeda, 2001).

In spite of the clearly different taxonomic positions of the genera Saccharothrix and Nocardiopsis, no distinction is currently possible, when attempting the identification of novel wild-type isolates that exhibit their morphological characteristics, without an extended chemotaxonomic and molecular analysis. An alternative approach, derived from analysis of the variability of $16 \mathrm{~S}$ rDNA sequences among different taxonomic groups and already in use for the development of specific probes at different taxonomic levels (Stahl \& Amann, 1991; McVeigh et al., 1995), is the design of genus-specific primers for the rapid identification of large numbers of strains. The application and usefulness of these genus-specific primers has already been reported for different members of the family Pseudonocardiaceae (Morón et al., 1999; Salazar et al., 2000). In this work, we have focused on the search for genus-specific primers for the genera Nocardiopsis and Saccharothrix, to be used in one-step molecular identification of strains of the two taxa. In addition, the recent taxonomic reclassification within the genus Saccharothrix and the creation of new, related genera necessitates an optimization of these tools to distinguish the genus Saccharothrix from these newly created taxa.

\section{METHODS}

Bacterial strains. The bacterial reference strains used in this study are listed in Table 1. Wild-type isolates were obtained from the laboratory culture collection. These strains were isolated from soils or decaying organic materials obtained from diverse geographical origins (Table 2). All strains were grown at $28{ }^{\circ} \mathrm{C}$ on YMG $(0.4 \%$ glucose, $0.4 \%$ yeast extract and $1.0 \%$ malt extract) agar or, in the case of some strains of Nocardiopsis, on alkaline yeast extract/malt medium [YMG with $1 \%(\mathrm{w} / \mathrm{v}) \mathrm{Na}_{2} \mathrm{CO}_{3}$ ].

Design of oligonucleotide primers. Sequence comparison and analysis were carried out using programs from the University of Wisconsin GCG package (version 7.2). Alignments of the $16 \mathrm{~S}$ region were performed using the multiple alignment program CLUSTAL W (Thompson et al., 1994) to determine the regions conserved only among Nocardiopsis or Saccharothrix species, from which the genus-specific primers were derived. The alignment is available as supplementary material in IJSEM Online (http:// ijs.sgmjournals.org/). The genus specificity of oligonucleotides was tested against all DNA sequences available in GenBank with the program FASTA. The melting temperature $\left(T_{\mathrm{m}}\right)$ was estimated using the formulae of Thomas and Dancis and the Lathe formulae (quoted in Stahl \& Amann, 1991). Relative $T_{\mathrm{m}}$ values obtained using $0.3 \mathrm{M}$ as a standard salt concentration helped to design pairs of primers with similarly high melting temperatures. The probabilities 
Table 1. Reference strains used in this study and results obtained from selective PCR amplifications with Stx2/Stx 1 and Nsp2/Nsp1

Amplification results: 1 , band of the expected size, 0 , absence of amplification products; NT, not tested.

\begin{tabular}{|c|c|c|c|c|c|}
\hline \multirow[t]{2}{*}{ Strain } & \multicolumn{4}{|c|}{ Stx2/Stx1 } & \multirow{2}{*}{$\frac{\text { Nsp2/Nsp1 }}{53^{\circ} \mathrm{C}}$} \\
\hline & $61{ }^{\circ} \mathrm{C}$ & $63^{\circ} \mathrm{C}$ & $65^{\circ} \mathrm{C}$ & $66^{\circ} \mathrm{C}$ & \\
\hline \multicolumn{6}{|l|}{ Nocardiopsaceae } \\
\hline N. dassonvillei subsp. albirubida ATCC $23612^{\mathrm{T}}$ & 0 & 0 & 0 & 0 & 1 \\
\hline N. dassonvillei subsp. dassonvillei ATCC $43517^{\mathrm{T}}$ & 0 & 0 & 0 & 0 & 1 \\
\hline N. lucentensis ATCC $51300^{\mathrm{T}}$ & 0 & 0 & 0 & 0 & 1 \\
\hline$N$. listeri ATCC $27442^{\mathrm{T}}$ & 0 & 0 & 0 & 0 & 1 \\
\hline N. prasina ATCC $35940^{\mathrm{T}}$ & 0 & 0 & 0 & 0 & 1 \\
\hline Thermobifida alba DSM $43695^{\mathrm{T}}$ & NT & NT & NT & NT & 0 \\
\hline \multicolumn{6}{|l|}{ Actinosynnemataceae } \\
\hline S. syringae DSM $43886^{\mathrm{T}}$ & 1 & 1 & 1 & 1 & 0 \\
\hline S. coeruleofusca DSM $43679^{\mathrm{T}}$ & 1 & 1 & 1 & 1 & 0 \\
\hline S. mutabilis subsp. capreolus DSM $40225^{\mathrm{T}}$ & 1 & 1 & 1 & 1 & 0 \\
\hline S. mutabilis subsp. mutabilis DSM $43853^{\mathrm{T}}$ & 1 & 1 & 1 & 1 & 0 \\
\hline S. mutabilis subsp. mutabilis NRRL B-16077 & 1 & 1 & 1 & 1 & 0 \\
\hline S. espanaensis DSM $44229^{\mathrm{T}}$ & 1 & 1 & 1 & 1 & 0 \\
\hline Lechevalieria aerocolonigenes ATCC 39243 & 1 & 1 & 0 & 0 & 0 \\
\hline Lechevalieria aerocolonigenes NRRL B-3298 & 1 & 1 & 0 & 0 & 0 \\
\hline Lechevalieria flava DSM $43885^{\mathrm{T}}$ & 1 & 1 & 0 & 0 & 0 \\
\hline Lentzea waywayandensis NRRL B-16159 & 1 & 1 & 1 & 0 & 0 \\
\hline Lentzea albidocapillata ATCC $51859^{\mathrm{T}}$ & 1 & 1 & 1 & 0 & 0 \\
\hline Crossiella cryophila NRRL B-16238 & 1 & 1 & 1 & 0 & 0 \\
\hline Actinosynnema pretiosum ATCC $31281^{\mathrm{T}}$ & 1 & 0 & 0 & 0 & 0 \\
\hline Actinosynnema mirum ATCC $29888^{\mathrm{T}}$ & 1 & 0 & 0 & 0 & 0 \\
\hline Kutzneria viridogrisea ATCC $25242^{\mathrm{T}}$ & 1 & 0 & 0 & 0 & 0 \\
\hline Kutzneria albida ATCC $25243^{\mathrm{T}}$ & 1 & 0 & 0 & 0 & 0 \\
\hline \multicolumn{6}{|l|}{ Pseudonocardiaceae } \\
\hline 'Saccharomonospora caesia' ATCC 49227 & 0 & 0 & 0 & 0 & 0 \\
\hline Saccharomonospora azurea ATCC $43670^{\mathrm{T}}$ & 0 & 0 & 0 & 0 & 0 \\
\hline Saccharomonospora cyanea ATCC $43724^{\mathrm{T}}$ & 0 & 0 & 0 & 0 & 0 \\
\hline Saccharomonospora viridis ATCC $15386^{\mathrm{T}}$ & 0 & 0 & 0 & 0 & 0 \\
\hline Amycolatopsis orientalis NRRL 2452 & 0 & 0 & 0 & 0 & 0 \\
\hline Amycolatopsis orientalis ATCC 21425 & 0 & 0 & 0 & 0 & 0 \\
\hline Amycolatopsis sulphurea NRRL $2282^{\mathrm{T}}$ & 0 & 0 & 0 & 0 & 0 \\
\hline Kibdelosporangium aridum subsp. largum ATCC $39922^{\mathrm{T}}$ & 0 & 0 & 0 & 0 & 0 \\
\hline \multicolumn{6}{|l|}{ Micromonosporaceae } \\
\hline Micromonospora chalcea ATCC $12452^{\mathrm{T}}$ & 0 & 0 & 0 & 0 & 0 \\
\hline Micromonospora carbonacea ATCC $27114^{\mathrm{T}}$ & 0 & 0 & 0 & 0 & 0 \\
\hline Micromonospora echinospora NRRL 2995 & 0 & 0 & 0 & 0 & 0 \\
\hline Micromonospora sp. NRRL 3275 & 0 & 0 & 0 & 0 & 0 \\
\hline Actinoplanes auranticolor ATCC $15330^{\mathrm{T}}$ & 0 & 0 & 0 & 0 & 0 \\
\hline Actinoplanes philippinensis ATCC $12427^{\mathrm{T}}$ & 0 & 0 & 0 & 0 & 0 \\
\hline Dactylosporangium auranticum ATCC $23491^{\mathrm{T}}$ & 0 & 0 & 0 & 0 & 0 \\
\hline 'Dactylosporangium vescum’ ATCC 39499 & 0 & 0 & 0 & 0 & 0 \\
\hline Pilimelia anulata ATCC $25604^{\mathrm{T}}$ & 0 & 0 & 0 & 0 & 0 \\
\hline \multicolumn{6}{|l|}{ Streptosporangiaceae } \\
\hline Nonomuraea africana ATCC $35107^{\mathrm{T}}$ & 0 & 0 & 0 & 0 & 0 \\
\hline \multicolumn{6}{|l|}{ Streptomycetaceae } \\
\hline 'Streptomyces cattleya' ATCC 35852 & 0 & 0 & 0 & 0 & 0 \\
\hline 'Streptomyces avermitilis' ATCC 31267 & 0 & 0 & 0 & 0 & 0 \\
\hline Streptomyces hygroscopicus subsp. hygroscopicus ATCC $27438^{\mathrm{T}}$ & 0 & 0 & 0 & 0 & 0 \\
\hline
\end{tabular}


Table 2. Wild-type isolates used in PCR experiments with genus-specific primers Nsp2/Nsp1 and Stx2/Stx1

Amplification results: 1 , band of the expected size; 0 , absence of amplification products.

\begin{tabular}{|c|c|c|c|c|}
\hline Strain & Country & Source & Nsp1/Nsp2 & Stx2/Stx1 \\
\hline \multicolumn{5}{|l|}{ Nocardiopsis spp. } \\
\hline $98-52-146 A^{* \dagger}, 98-52-148 A^{* \dagger}, 98-52-149 A^{* \dagger}, 98-52-204 A^{* \dagger}$ & Australia & Decaying leaves & 1 & 0 \\
\hline $98-52-173 \mathrm{~A} \dagger$ & Australia & Soil & 1 & 0 \\
\hline $99-20-007 A^{*}$ & Belize & Soil & 1 & 0 \\
\hline $97-38-018 A^{*}$ & Equatorial Guinea & Soil & 1 & 0 \\
\hline $99-21-444 A^{* \dagger}$ & Madagascar & Soil & 1 & 0 \\
\hline 98-08-290A*, 99-08-186A*†, 99-20-430A & Mexico & Soil & 1 & 0 \\
\hline $98-29-191 A^{*}$ & South Africa & Soil & 1 & 0 \\
\hline $98-10-097 A^{*} \dagger$ & Spain & $\begin{array}{l}\text { Decomposing } \\
\text { organic material }\end{array}$ & 1 & 0 \\
\hline \multicolumn{5}{|l|}{ Saccharothrix spp. } \\
\hline $98-05-051 \mathrm{~A}^{* \dagger}$ & Costa Rica & Soil & 0 & 1 \\
\hline 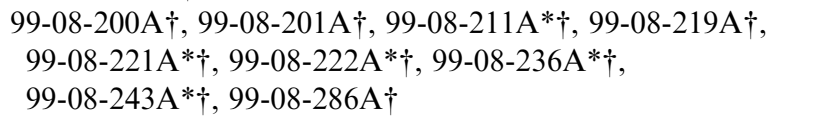 & Mexico & Soil & 0 & 1 \\
\hline $99-15-236 \mathrm{~A} \dagger, 99-19-550 \mathrm{~A}^{* \dagger}$ & Senegal & Soil & 0 & 1 \\
\hline 98-10-099A* & Spain & $\begin{array}{l}\text { Decomposing } \\
\text { organic material }\end{array}$ & 0 & 1 \\
\hline $\begin{array}{l}98-41-143 A^{*}, 98-41-281 A^{*}, 98-41-338 A^{*}, 98-48-079 A^{\dagger} \\
\text { Streptomyces spp. }\end{array}$ & South Africa & Soil & 0 & 1 \\
\hline $99-08-217 \mathrm{~A} \uparrow, 99-08-218 \mathrm{~A} \dagger$ & Mexico & Soil & 0 & 0 \\
\hline \multicolumn{5}{|l|}{ Nocardia spp. } \\
\hline $98-37-068 A^{*} \dagger$ & French Guyana & Soil & 0 & 0 \\
\hline $99-08-244 A^{* \dagger}$ & Mexico & Soil & 0 & 0 \\
\hline $97-21-103 A^{*} \dagger$ & West Indies & Soil & 0 & 0 \\
\hline \multicolumn{5}{|l|}{ Unidentified actinomycetes } \\
\hline $97-39-041 \mathrm{~A}$ & Costa Rica & Soil & 0 & 0 \\
\hline $99-08-103 \mathrm{~A}$ & Niger & Soil & 0 & 0 \\
\hline 98-29-235A, 98-31-122A $\dagger$ & South Africa & Soil & 0 & 0 \\
\hline $98-10-149 \mathrm{~A}$ & Spain & $\begin{array}{l}\text { Decomposing } \\
\text { organic material }\end{array}$ & 0 & 0 \\
\hline $98-21-170 \mathrm{~A}$ & Thailand & Soil & 0 & 0 \\
\hline
\end{tabular}

* Sequenced strain.

$\dagger$ Strain subjected to fatty acid analysis.

of primer-dimer formation and autofolding were also studied in order to keep them as low as possible. The oligonucleotides designed were supplied by Pharmacia Biotech.

DNA extraction. Total genomic DNA from the different micro-organisms used in this study was recovered and purified as described previously (Lee \& Taylor, 1990).

PCR amplification. DNA preparations were used as template DNA for Taq polymerase. Reactions were performed in a final volume of $25 \mu$ containing $0 \cdot 2 \mathrm{mM}$ of each of the four dNTPs (Roche), $0 \cdot 1 \mu \mathrm{M}$ of each primer, $5 \mu$ of the extracted DNA (1:100 dilution) and 0.5 U Taq polymerase (Appligene) with its appropriate reaction buffer. Controls without bacterial DNA were included for each PCR experiment. Amplifications were performed in a Perkin Elmer Cetus DNA thermal cycler 480, according to the following profile: 40 cycles of $30 \mathrm{~s}$ at $93{ }^{\circ} \mathrm{C}, 30 \mathrm{~s}$ at $55^{\circ} \mathrm{C}$ (primers Nsp2/Nsp1) or $61-66^{\circ} \mathrm{C}$ (primers Stx2/Stx 1 ) and $2 \mathrm{~min}$ at $72^{\circ} \mathrm{C}$, followed by $10 \mathrm{~min}$ at $72{ }^{\circ} \mathrm{C}$. Amplification products were analysed by electrophoresis $\left(5 \mathrm{~V} \mathrm{~cm}^{-1}\right)$ in standard $1.2 \%$ (w/v) agarose gels stained with ethidium bromide or using a Ready-to-Run Separation Unit (Amersham Pharmacia Biotech).

DNA sequencing. The PCR primers $27 \mathrm{f}$ and $1525 \mathrm{r}$ (Lane, 1991) were used for amplification of the 16S rDNA. The $1500 \mathrm{bp}$ PCR products were purified and used as templates in sequencing reactions using the primers $27 \mathrm{f}, 357 \mathrm{f}$, 530f, 926f, 1392f, 1525r, 1110r, 685r and 357r (Lane, 1991). Amplified products were sequenced using an ABI PRISM Dye Terminator cycle sequencing kit (Perkin Elmer). The GenBank accession numbers for the 16S rDNA sequences obtained in this study are as follows: Nocardiopsis sp. isolates 98-38-018A, 98-10-097A, 98-29-191A, 98-52-146A, 98-52-148A, 98-52-149A, 98-52-204A, 98-08-290A, 99-21-444A, 99-20-007A and 99-08-186A, respectively AF328401-AF328410 and AF361322; Saccharothrix sp. isolates 97-38-018A, 98-05-051A, 99-08-221A, 99-08-222A, 99-08-236A, 98-10-099A, 98-41-143A, 98-41-338A, 98-41- 
281A, 99-08-211A, 99-08-143A and 99-19-550A, respectively AF328411-AF328418 and AF361323-AF361325; Nocardia sp. isolates 99-37-68A, 99-08-244A and 97-21-103A, AF421563-AF421565.

Data analysis. Sequences were assembled using the GCG Fragment Assembly system. Alignments of the 16S rDNA sequences were performed using the multiple alignment program CLUSTAL W (Thompson et al., 1994; IntelliGenetics).

The phylogenetic analysis was completed with 16S rDNA sequences of Nocardiopsis spp. and Saccharothrix spp. Phylogenetic analysis of the aligned sequences was performed using maximum-parsimony analysis with the branch-and-bound algorithm of PAUP version 4.0 (Swofford, 1993), with gaps treated as missing data. Data were resampled with 1000 bootstrap replicates (Felsenstein, 1985) by using the heuristic search option of PAUP. The percentage of bootstrap replicates that yielded each grouping was used as a measure of statistical confidence. A grouping found on $95 \%$ of bootstrap replicates was considered statistically significant.

Whole-cell fatty acid composition. Cultures were grown as confluent patches on TSB agar (BBL) at $28^{\circ} \mathrm{C}$ for 4 days. Vegetative growth was then scraped (100-200 mg) and fatty acid methyl esters (FAMEs) were prepared according to Miller (1982). Analysis of FAMEs was carried out by capillary gas chromatography using a Hewlett Packard model 5890 gas chromatograph/MIDI system (Microbial ID) equipped with a phenyl methyl silicone column $(0.2 \mathrm{~mm} \times 25 \mathrm{~m})$. Chromatography conditions were as recommended by the manufacturer. Individual FAME identification was achieved using the MIS software (Microbial ID) and clustering analysis was performed using the statistical software package S-Plus 2000 (Mathsoft).

\section{RESULTS AND DISCUSSION}

\section{Design of genus-specific primers}

The design of two sets of genus-specific pairs of primers for the selective amplification of the $16 \mathrm{~S}$ rDNA regions of the genera Nocardiopsis and Saccharothrix has been based on the search for conserved sequences within each genus after a comparative analysis of the variable regions of known 16S rRNA sequences. An alignment of the GenBank 16S rRNA/DNA sequences that were used for the design of the primers is available as supplementary material in IJSEM Online (http://ijs.sgmjournals.org/).

In the case of the genus Nocardiopsis, two regions, covering nucleotides 440-465 and 995-1020, corresponding to nucleotide positions of the Streptomyces ambofaciens 16S rDNA (Pernodet et al., 1989), were found to be highly conserved among the different species of the genus. In contrast, the highly conserved ribosomal sequences among members of the genus Saccharothrix were found at the beginning of the gene, around positions $80-100$ and 590-615. These sequence homologies were high enough to consider the design of genus-specific primers for the two genera. The two genus-specific primers Nsp2 (5'-TCTCTTGGGGTTGACGGTAG-3') and Nsp1 (5'-TAAATGACCTCACATCTCT- $3^{\prime}$ ) that were designed for the genus
Nocardiopsis nested respectively at positions 445-464 and 996-1014 of the 16S rDNA, whereas the two genus-specific primers for the genus Saccharothrix, Stx2 (5'-AAGGCCCTTCGGGGTACACGAG-3') and Stx 1 (5'-TCGACCGCAGGCTCCACG-3'), respectively hybridized at positions 80-101 and 594-611.

\section{Specificity of the primers for the genus Nocardiopsis}

The sequence alignment with primer Nsp1 showed total identity to the sequences of $N$. dassonville $i$ subsp. albirubida, $N$. dassonvillei subsp. dassonvillei, $N$. lucentensis and $N$. kunsanensis only (see supplementary material). In the other species studied, one to six nonmatched positions were observed within the annealing region. The alignment with Thermobifida fusca and Thermobifida alba, also members of the family Nocardiopsaceae, showed five non-matched positions with the primer sequence. This lack of identity increased when the primer was aligned with the sequences of species of the genera Saccharothrix, Lentzea, Lechevalieria, Crossiella, Actinosynnema and Kutzneria, where up to eight non-matching positions were observed. The sequence identity of the primer decreased even more when the same region was considered in other actinomycetes, such as the genera Saccharomonospora, Amycolatopsis, Nonomuraea, Actinomadura, Micromonospora and Streptomyces.

The primer Nsp2 showed only one or two mismatching positions in the Nocardiopsis species studied, with the exception of $N$. trehalosi, where four mismatching positions were observed. A similar number, three mismatching positions, was found in members of the genus Thermobifida. The primer showed no homology with Saccharothrix spp. and other related genera, with up to 10 mismatching positions (see supplementary material).

When the primer pair Nsp2/Nsp1 was tested in PCR using an annealing temperature of $53{ }^{\circ} \mathrm{C}$, defined as optimal for them, we obtained the expected amplification product of $575 \mathrm{bp}$ from all the type strains of the genus Nocardiopsis tested ( $N$. dassonvillei subsp. albirubida ATCC $23612^{\mathrm{T}}$, N. dassonvillei subsp. dassonvillei ATCC $43517^{\mathrm{T}}, N$. lucentensis ATCC $51300^{\mathrm{T}}, N$. listeri ATCC $27442^{\mathrm{T}}$ and $N$. prasina ATCC $35940^{\mathrm{T}}$ ) (Fig. 1). No amplification product was obtained with DNA from different Saccharothrix species or from other actinomycetes taxa, including the closely related genus Thermobifida (Table 1). The same results were obtained when amplifications were performed at different annealing temperatures $\left(51,55\right.$ and $57^{\circ} \mathrm{C}$ ), indicating that the genus specificity of the primers was not affected over a wide range of temperatures, of $51-57^{\circ} \mathrm{C}$.

\section{Specificity of the primers for the genus Saccharothrix}

When comparing the sequence alignments with the primers specific for the genus Saccharothrix (see supplementary material), we observed total identity or 
(a) L. $1234456778991011121314151617181920 \mathrm{~L}$

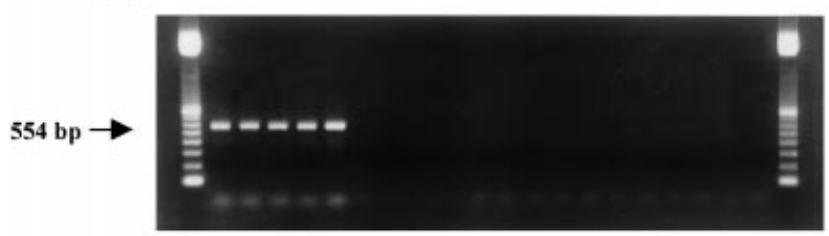

(b) $\quad$ L $12234456678991011121314151617181920 \mathrm{~L}$

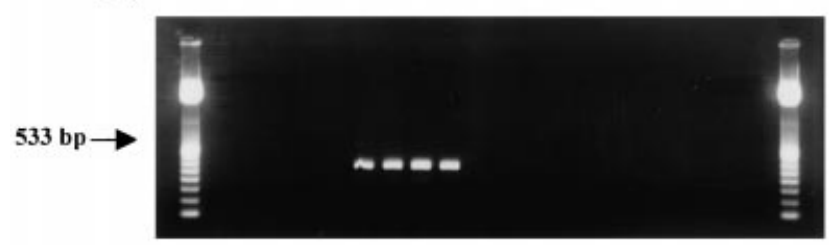

Fig. 1. Agarose gel electrophoresis of $P C R$ products from DNA. (a) Selective amplification at $53{ }^{\circ} \mathrm{C}$ of a $575 \mathrm{bp}$ fragment using primers Nsp2/Nsp1 specific for the genus Nocardiopsis. (b) Selective amplification at $66^{\circ} \mathrm{C}$ of a $545 \mathrm{bp}$ fragment using primers Stx2/Stx1 specific for the genus Saccharothrix. Lanes: L, DNA size ladder; $1, N$. dassonvillei subsp. albirubida ATCC $23612^{\top} ; 2$, N. dassonvillei subsp. dassonvillei ATCC $43517^{\top} ; 3, N$. lucentensis ATCC $51300^{\top} ; 4$, N. listeri ATCC $27442^{\top} ; 5, N$. prasina ATCC $35940^{\top} ; 6$, S. syringae DSM $43886^{\top} ; 7$, S. coeruleofusca DSM $43679^{\top} ; 8$, S. mutabilis subsp. mutabilis DSM 43853' $; 9$, S. espanaensis DSM 44229 ${ }^{\top}$; 10, Lentzea waywayandensis NRRL B$16159^{\top}$; 11, Lentzea albidocapillata ATCC $51859^{\top}$; 12 , Crossiella cryophila NRRL B-16238 ${ }^{\top}$; 13, Lechevalieria aerocolonigenes ATCC $39243^{\top} ; 14$, Lechevalieria flava DSM 43885 $;$; 15 , Actinosynnema pretiosum ATCC $31281^{\top}$; 16, Kutzneria viridogrisea ATCC $25242^{\top}$; 17 , Amycolatopsis orientalis NRRL 2452; 18, Kibdelosporangium aridum subsp. largum ATCC $39922^{\top}$; 19, Micromonospora carbonacea ATCC 27114 ${ }^{\top}$; 20, control reaction without DNA.

a single mismatch in the members of this genus in the region used to design the forward primer Stx2. The same sequence was also contained in members of the related genera Lentzea, Lechevalieria, Crossiella, Kutzneria and Actinosynnema, as well as in members of the genus Nocardiopsis, and it was less well conserved in the rest of the actinomycete taxa studied.

In contrast, the reverse primer Stx1 showed total identity to all members of the genus Saccharothrix, with the exception of two species, $S$. texasensis and $S$. tangerinus, where one and five non-matching positions, respectively, were observed. In the new related genera Lechevalieria and Crossiella, as well as in the genera Lentzea, Kutzneria and Actinosynnema, three to five non-matching positions were also observed in the extending end of the primer. This lack of homology increased to nine non-matching positions with different sequences of the genus Nocardiopsis, which ensured that the amplification reaction with the pair of primers Stx2/Stx1 was specific to sequences from Saccharothrix and other related taxa. The primer Stx2 had been designed originally to match the rDNA sequences of former Saccharothrix species recently transferred to the genera Lentzea, Lechevalieria and

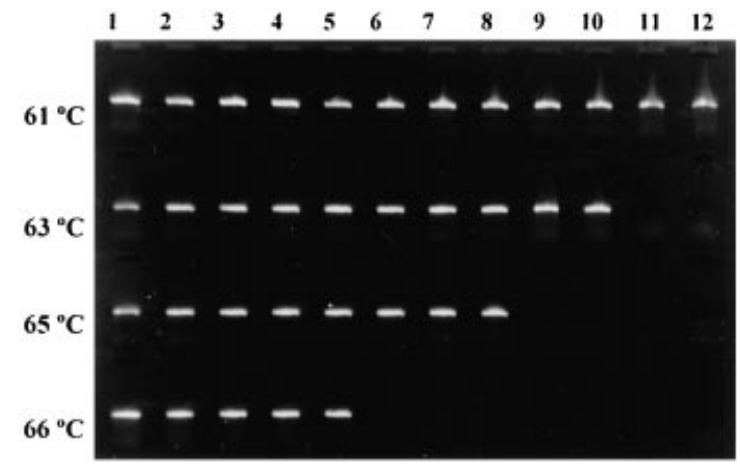

Fig. 2. Effect of annealing temperature on selective amplification with primers Stx2/Stx 1 of members of the family Actinosynnemataceae. Lanes: 1 , S. syringae DSM $43886^{\top} ; 2$, S. coeruleofusca DSM 43679 $;$, 3, S. espanaensis DSM 44229 ${ }^{\top} ; 4$, S. mutabilis subsp. capreolus DSM $40225^{\top} ; 5$, S. mutabilis subsp. mutabilis DSM 43853 ${ }^{\mathrm{T}}$; 6, Lentzea waywayandensis NRRL B$16159^{\top}$; 7, Lentzea albidocapillata ATCC 51859'; 8, Crossiella cryophila NRRL B-16238 ${ }^{\top}$; 9, Lechevalieria aerocolonigenes NRRL $\mathrm{B}-3298^{\top} ; 10$, Lechevalieria flava DSM $43885^{\top} ; 11$, Actinosynnema pretiosum ATCC $31281^{\mathrm{T}}$; 12, Kutzneria viridogrisea ATCC $25242^{\top}$.

Crossiella. The use of low annealing temperatures $\left(61{ }^{\circ} \mathrm{C}\right)$ ensured the amplification of sequences from species of the genus Saccharothrix, as well as members of other genera of the family Actinosynnemataceae, but no amplification was detected from strains of the genus Nocardiopsis or members of other actinomycete families (Table 1). The taxonomic reorganization of the genus Saccharothrix has required an optimization of the amplification conditions and, therefore, different annealing temperatures ranging from 61 to $66^{\circ} \mathrm{C}$ were tested to increase the specificity of the amplification reaction (Fig. 2). When PCRs were performed at $66{ }^{\circ} \mathrm{C}$, a specific amplification was obtained only with members of the genus Saccharothrix (Figs 1b and 2).

These data show that the two pairs of primers Nsp2/Nsp1 and Stx2/Stx1 allow the specific identification of all the tested strains belonging to these genera, in spite of the small differences observed in their sequences. The high specificity for the targeted sequences of at least one of the oligonucleotides in each pair of primers, together with the low-stringency conditions defined for the annealing reactions, ensures amplifications not as selective as to distinguish between sequences of the same genus, which differ in a few nucleotides, but specific enough to identify members of these genera selectively.

\section{Identification of wild-type isolates and evaluation of their diversity}

One of the purposes of the design of these primers was the rapid detection of members of the two genera among the large numbers of environmental isolates that share morphological traits with the genera Nocar- 


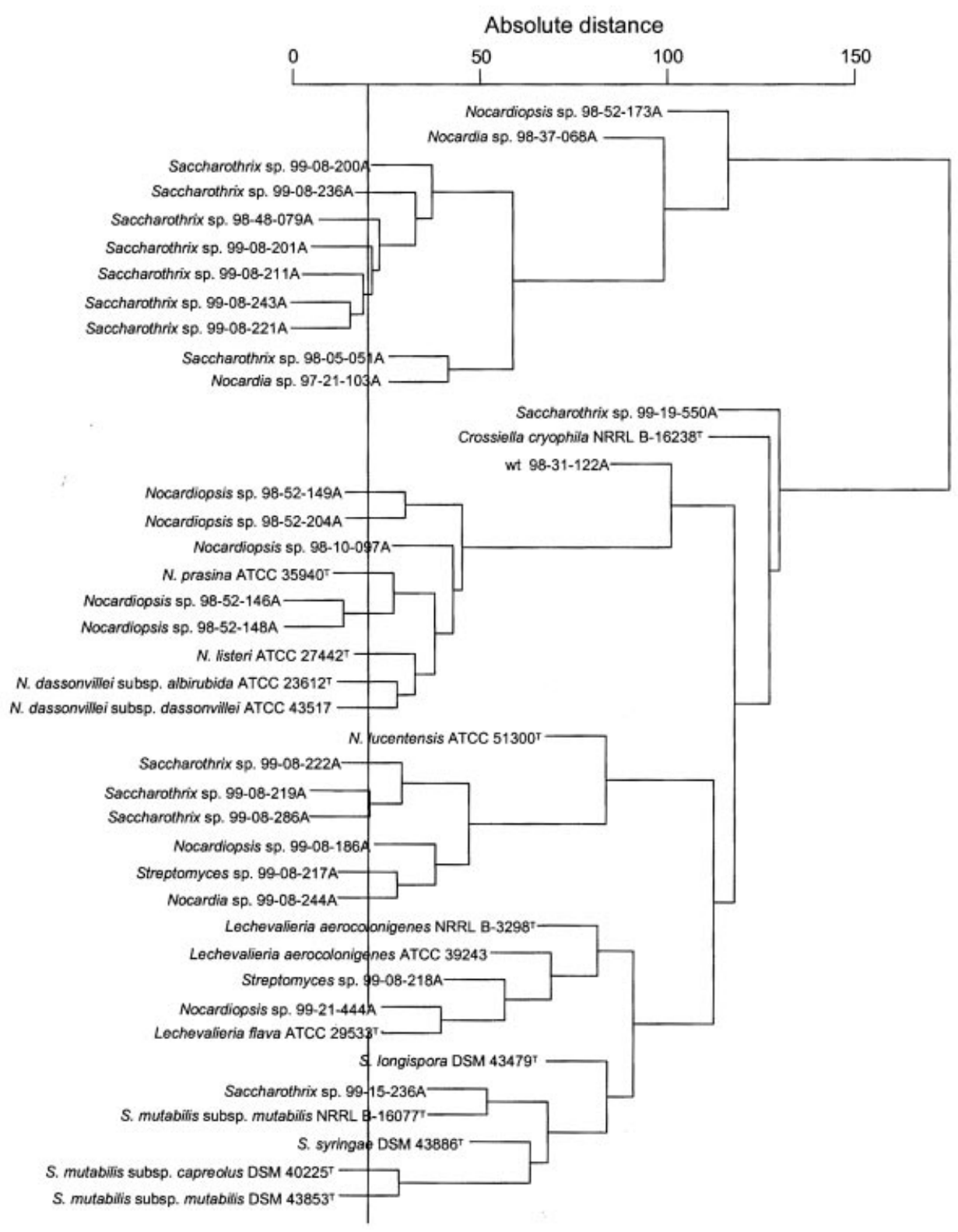

Fig. 3. Diversity of wild-type strains identified with primers specific for the genera Nocardiopsis and Saccharothrix and their relationships to reference strains of the two genera. The dendrogram was generated by treating the Euclidian distances of the fatty acids with UPGMA. Reference strains are those included in Table 1.

diopsis and Saccharothrix. We selected from our culture collection a group of 41 wild-type isolates with these morphological characteristics that, in the absence of the required extended chemotaxonomic study, had never been definitively assigned to any of these genera. DNA was extracted from each of the 41 wild-type isolates and tested with both pairs of genus-specific primers, in the case of primers Stx1/Stx2, using two different temperatures $\left(61\right.$ or $\left.66^{\circ} \mathrm{C}\right)$ for the annealing conditions. A positive specific amplification was only obtained in 30 isolates, of which 13 and 17 strains, respectively, under all conditions, were amplified with the primers for Nocardiopsis and Saccharothrix (Table
2). These strains, although they were obtained from quite diverse geographical origins and using a wide range of isolation conditions, also shared, in some cases, their origin and morphological characteristics with other strains that did not amplify and probably correspond to other related taxa.

In an attempt to determine the diversity of our wildtype isolates, identified to the genus level with the specific primers, and evaluate their relationships with reference strains of the two genera, we determined the fatty acid composition of a representative group of strains. Among other chemotaxonomic markers, the 


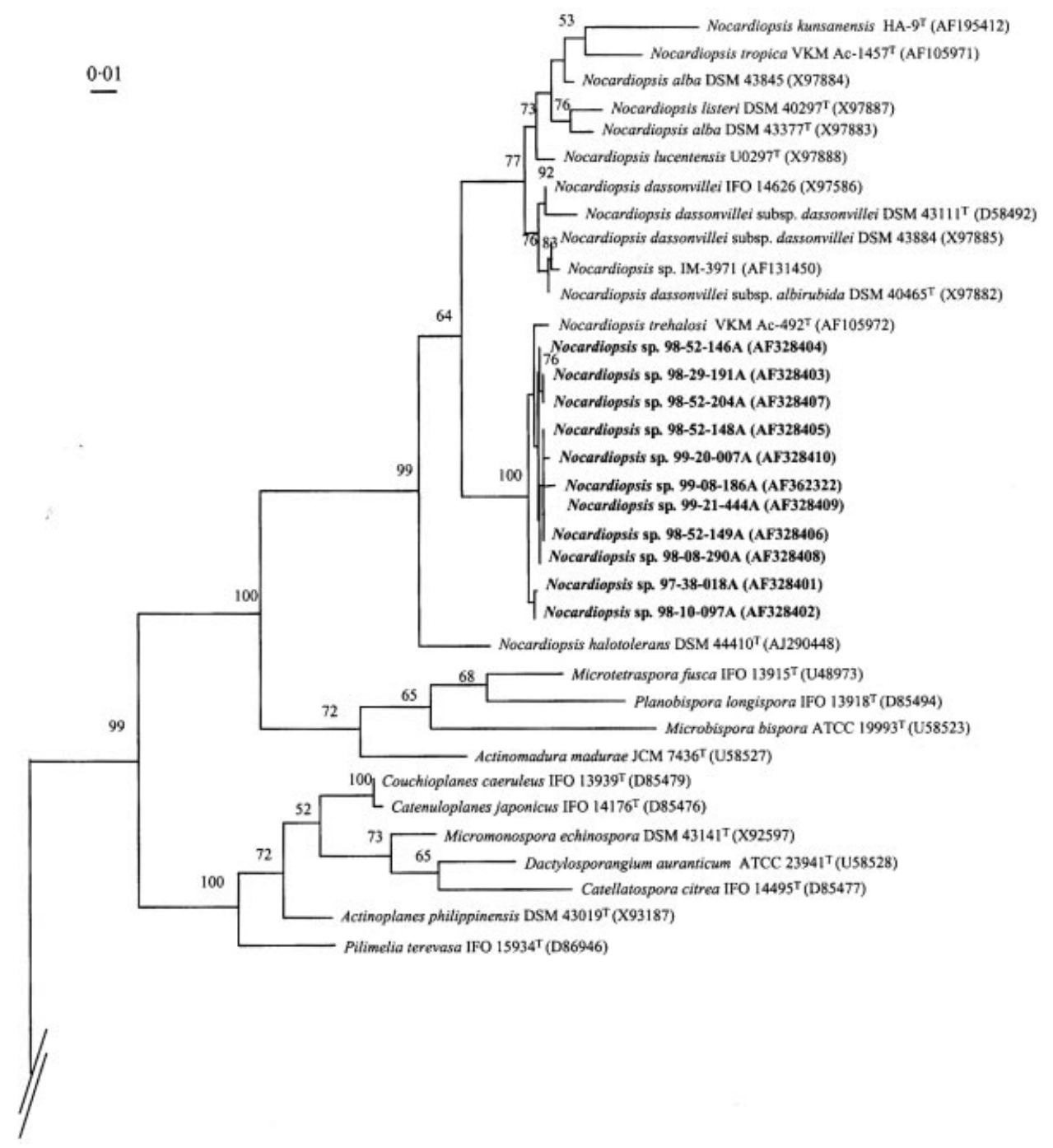

Fig. 4. For legend see facing page.

genera Nocardiopsis and Saccharothrix can be distinguished by their fatty acid composition. The genus Nocardiopsis, with a $3 \mathrm{~d}$ fatty acid type, contains substantial amounts of tuberculostearic acid (18:0$10 \mathrm{Me}$ ) and oleic acid (18:1-cis9), which are not normally present in the $3 \mathrm{f}$ type of the genus Saccharothrix, where 2-hydroxylated iso- and anteiso-branched fatty acids are detected (Grund \& Kroppenstedt, 1990; Kroppenstedt, 1985, 1992). Clustering analysis of the strains was based on their fatty acid patterns and the relationship among the strains was established in a dendrogram generated by treating the Euclidian distances of the fatty acids with the unweighted pair group method (UPGMA) (Fig. 3). Almost all the reference strains from the genera Nocardiopsis, Saccharothrix and other related taxa appeared to be clearly separated in different branches and clustered tightly, with the exception of $N$. lucentensis ATCC $51300^{\mathrm{T}}$, which appeared as a single branch on the dendrogram. Among the wild-type strains, we found that most of the strains that were amplified positively with the primers for Nocardiopsis clustered with reference strains of Nocardiopsis. We also observed some exceptions, of strains clustering with members of Lechevalieria (isolate 99-21-444A), with other wild-type strains not amplified by the primers (isolate 99-08186A) or not related to any of the strains in the study (isolate 98-52-173A). In the case of the strains identified with the primers as Saccharothrix, most of them appeared to be grouped in separate clusters not related to the branch defined by the fatty composition of most reference strains of this genus. Isolate $99-19-550 \mathrm{~A}$, identified as Saccharothrix by amplification at $66^{\circ} \mathrm{C}$, appeared as a single branch, closely related to Crossiella cryophila.

In order to confirm the genus assignment of our isolates and to discard the possibility of a lack of specificity of the primers as the source of the phenotypic heterogeneity among our strains revealed by the 


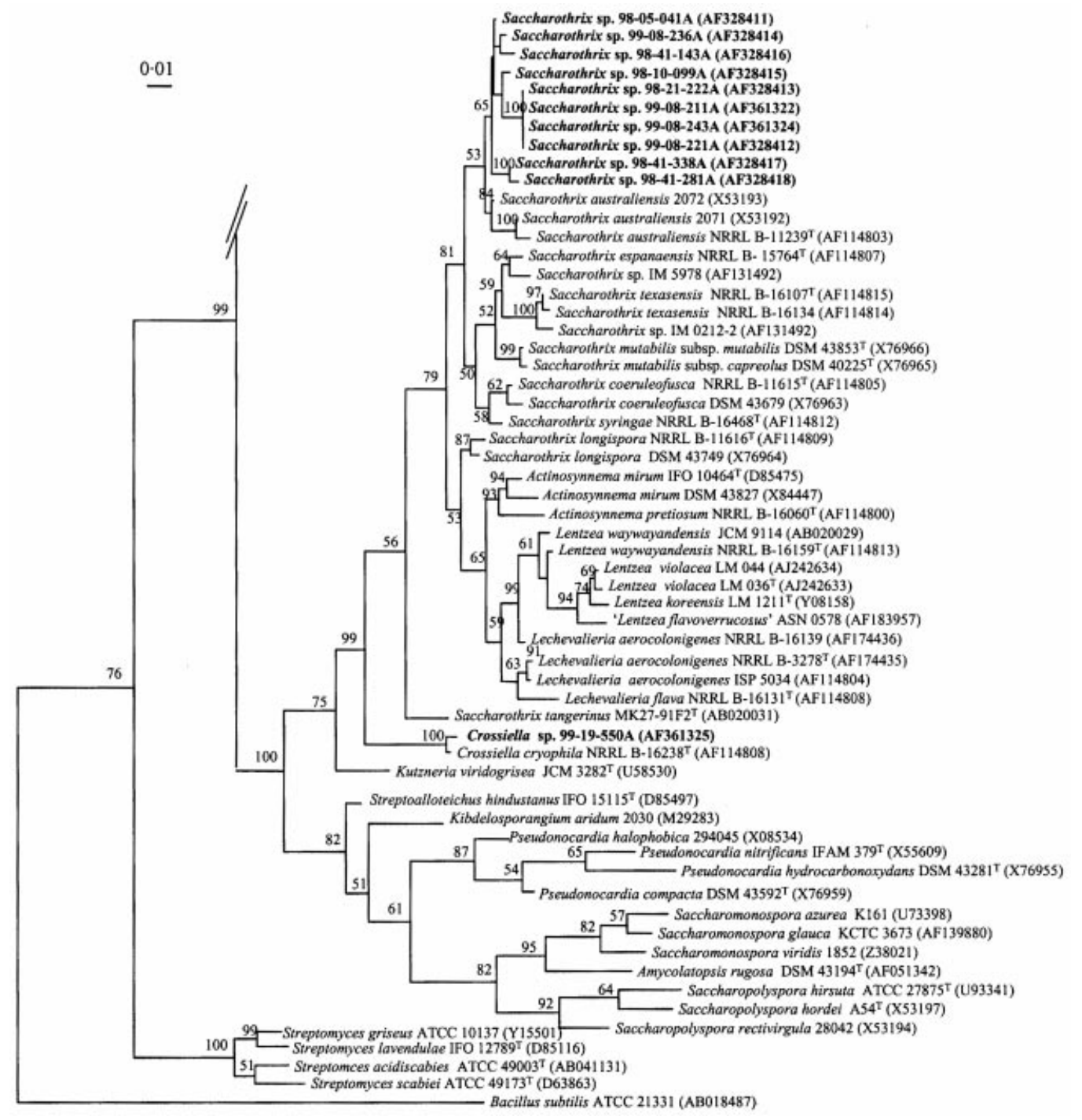

Fig. 4. Phylogenetic tree showing the position of wild-type strains of the genera Nocardiopsis and Saccharothrix derived from 16S rDNA analysis using the maximum-parsimony method in PAUP 4.0. Numbers above branches indicate bootstrap percentages from 1000 replicates, which were used as a measure of statistical confidence.

fatty acid composition, we determined the almost complete nucleotide sequence of the $16 \mathrm{~S}$ rDNAs of a representative group of 25 wild-type strains selected from different origins, including 11 isolates identified as Saccharothrix, 11 strains as Nocardiopsis and three strains that did not amplify with the primers (Table 2). In all cases, we found that the annealing sequence of each pair of primers was highly conserved among the strains that were amplified positively, confirming the specificity of each pair of primers. Among the strains assigned to the genus Nocardiopsis, the level of sequence similarity for the complete $16 \mathrm{~S}$ rDNA sequence ranged from 100 to $99.6 \%$, indicating the high sequence similarity within this group of strains in spite of their different origin. A close relationship was observed for all these isolates with the species $N$. trehalosi (sequence similarity 99.8-100\%). In fact, the nucleotide sequence of the annealing region of primer Nsp2 in these strains exactly matched the sequence of $N$. trehalosi, which presents four mismatches with Nsp2 in this region. The isolates identified as Saccharothrix presented greater sequence heterogeneity, but the similarity levels among the strains still remained very high, ranging from $99 \cdot 3$ to $98.5 \%$. The closest relationship of these strains with reference species of this genus was found with $S$. australiensis, where the levels of sequence similarity were $99 \cdot 5-97 \cdot 4 \%$. The three strains sequenced that did not amplify with any of the primers showed 98-99\% sequence similarity to different species of the genus Nocardia.

A phylogenetic tree based on these $16 \mathrm{~S}$ rDNA sequences was built using the maximum-parsimony method (Fig. 4), showing the inter- and intraspecific 
relationships of the wild-type strains to reference strains of the genera Saccharothrix and Nocardiopsis and other members of the order Actinomycetales. The topology of the tree confirms previous studies that have determined the taxonomic reorganization of the genus Saccharothrix, which contrasts with the monophyletic lineage of the genus Nocardiopsis (Labeda \& Kroppenstedt, 2000; Evtushenko et al., 2000; Labeda et al., 2001; Labeda, 2001). Almost all the wild-type strains of the genus Saccharothrix appear associated in closely related branches, in spite of the observed differences in their fatty acid compositions revealed in the clustering analysis. Their closest relationship to members of the species $S$. australiensis is not highly supported by the bootstrapping values $(53 \%)$ and, from the available data, none of these wild-type isolates can be associated with any of the species included in the study. The existence of this cluster suggests the existence of novel species within the genus Saccharothrix. In contrast, isolate 99-19-550A, confirmed as Saccharothrix by amplification at high temperature, was placed in a separate branch, clustering tightly with Crossiella cryophila, and must represent another strain of the same species (bootstrapping value of $100 \%$ ). Surprisingly, strain 9919-550A, which presents $99 \%$ 16S rDNA sequence similarity to Crossiella cryophila, contains five nonmatching nucleotides with the sequence of Crossiella in the region that corresponds exactly to the hybridization sequence of primer Stx1, which explains the amplification of this isolate with primers Stx2/Stx1.

In contrast, all the wild-type isolates of the genus Nocardiopsis clustered tightly with $N$. trehalosi, in spite of their diverse origin. In this case, this single cluster was strongly supported by bootstrapping analysis (bootstrapping value of $100 \%$ ) and was clearly separated from other reference strains, as previously observed for N. trehalosi (Evtushenko et al., 2000).

In this work, we have presented the application of two new pairs of genus-specific primers as a simple method for the rapid identification of novel members of the genera Nocardiopsis and Saccharothrix from the large numbers of strains that are normally obtained in industrial isolation programmes. Our results with reference strains, as well as the high degree of conservation observed among the sequences of the wildtype isolates, validate the specificity of these new pairs of primers and support the usefulness of these tools for rapid distinction between the two genera and the tentative genus assignment of novel isolates of these taxa. Nevertheless, the phenotypic diversity of the wild-type strains obtained from quite different habitats contrasts with the high degree of conservation observed at the sequence level, especially in the case of members of the genus Nocardiopsis. This result can be only partially explained by their common exhibition of similar micromorphological characters, which were used as a selection criterion for this work. Further studies with these primers are required to evaluate the presence of novel members of these genera among isolates in our culture collection not suspected to belong to these taxa.

\section{REFERENCES}

Al-Tai, A. M. \& Ruan, J.-S. (1994). Nocardiopsis halophila sp. nov., a new halophilic actinomycete isolated from soil. Int J Syst Bacteriol 44, 474- 478.

Al-Zarban, S. S., Abbas, I., Al-Mussalam, A. A., Steiner, U., Stackebrandt, E. \& Kroppenstedt, R. M. (2002). Nocardiopsis halotolerans sp. nov., isolated from salt marsh soil in Kuwait. Int $J$ Syst Evol Microbiol 52, 525-529.

Chiba, S., Suzuki, M. \& Ando, K. (1999). Taxonomic re-evaluation of 'Nocardiopsis' sp. K-252 $2^{\mathrm{T}}$ (= NRRL $15532^{\mathrm{T}}$ ): a proposal to transfer this strain to the genus Nonomuraea as Nonomuraea longicatena sp. nov. Int J Syst Bacteriol 49, 1623-1630.

Chun, J., Bae, K. S., Moon, E. Y., Jung, S.-O., Lee, H. K. \& Kim, S.-J. (2000). Nocardiopsis kunsanensis sp. nov., a moderately halophilic actinomycete isolated from a saltern. Int J Syst Evol Microbiol 50, 1909-1913.

Evtushenko, L. I., Taran, V. V., Akimov, V. N., Kroppenstedt, R. M., Tiedje, J. M. \& Stackebrandt, E. (2000). Nocardiopsis tropica sp. nov., Nocardiopsis trehalosi sp. nov., nom. rev. and Nocardiopsis dassonvillei subsp. albirubida subsp. nov., comb. nov. Int J Syst Evol Microbiol 50, 73-81.

Felsenstein, J. (1985). Confidence intervals on phylogenies: an approach using the bootstrap. Evolution 39, 783-791.

Grund, E. \& Kroppenstedt, R. M. (1989). Transfer of five Nocardiopsis species to the genus Saccharothrix Labeda et al. 1984. Syst Appl Microbiol 12, 267-274.

Grund, E. \& Kroppenstedt, R. M. (1990). Chemotaxonomy and numerical taxonomy of the genus Nocardiopsis Meyer 1976. Int J Syst Bacteriol 40, 5-11.

Kämpfer, P., Busse, H.-J. \& Rainey, F. A. (2002). Nocardiopsis compostus sp. nov., from the atmosphere of a composting facility. Int $J$ Syst Evol Microbiol 52, 621-627.

Kroppenstedt, R. M. (1985). Fatty acid and menaquinone analysis of actinomycetes and related organisms. In Chemical Methods in Bacterial Systematics, vol. 20, pp. 173-199. Edited by M. Goodfellow \& D. E. Minnikin. New York: Academic Press.

Kroppenstedt, R. M. (1992). The genus Nocardiopsis. In The Prokaryotes, 2nd edn, pp. 996-1027. Edited by A. Balows, H. G. Trüper, M. Dworkin, W. Harder \& K.-H. Schleifer. New York: Springer.

Labeda, D. P. (1986). Transfer of "Nocardia aerocolonigenes" (Shinobu and Kawato 1960) Pridham 1970 into the genus Saccharothrix Labeda, Testa, Lechevalier, and Lechevalier 1984 as Saccharothrix aerocolonigenes sp. nov. Int J Syst Bacteriol 36, 109-110.

Labeda, D. P. (2001). Crossiella gen. nov., a new genus related to Streptoalloteichus. Int J Syst Evol Microbiol 51, 1575-1579.

Labeda, D. P. \& Kroppenstedt, R. M. (2000). Phylogenetic analysis of Saccharothrix and related taxa: proposal for Actinosynnemataceae fam. nov. Int J Syst Evol Microbiol 50, 331-336.

Labeda, D. P. \& Lechevalier, M. P. (1989). Amendment of the genus Saccharothrix Labeda et al. 1984 and descriptions of Saccharothrix espanaensis sp. nov., Saccharothrix cryophilis sp. nov., and Saccharothrix mutabilis comb. nov. Int J Syst Bacteriol 39, 420-423.

Labeda, D. P. \& Lyons, A. J. (1989). Saccharothrix texasensis sp. nov. and Saccharothrix waywayandensis sp. nov. Int J Syst Bacteriol 39, 355-358.

Labeda, D. P., Testa, R. T., Lechevalier, M. P. \& Lechevalier, H. A. (1984). Saccharothrix: a new genus of the Actinomycetales related to Nocardiopsis. Int J Syst Bacteriol 34, 426-431.

Labeda, D. P., Hatano, K., Kroppenstedt, R. M. \& Tamura, T. (2001). Revival of the genus Lentzea and proposal for Lechevalieria gen. nov. Int J Syst Evol Microbiol 51, 1045-1050.

Lane, D. J. (1991). 16S $/ 23 \mathrm{~S}$ rRNA sequencing. In Nucleic Acid Techniques in Bacterial Systematics, pp. 115-175. Edited by E. Stackebrandt \& M. Goodfellow. Chichester: Wiley. 
Lechevalier, M. P., de Bièvre, C. \& Lechevalier, H. A. (1977). Chemotaxonomy of aerobic actinomycetes: phospholipid composition. Biochem Ecol Syst 5, 249-260.

Lee, S. B. \& Taylor, J. N. (1990). Isolation of DNA from fungal mycelia and single spores. In PCR Protocols. A Guide to Methods and Applications, pp. 282-287. Edited by M. A. Innis, D. H. Gelfand, J. J. Sninsky \& T. J. White. San Diego: Academic Press.

Lee, S. D., Kim, E. S., Roe, J.-H., Kim, J., Kang, S.-O. \& Hah, Y. C. (2000). Saccharothrix violacea sp. nov., isolated from a gold mine gave, and Saccharothrix albidocapillata comb. nov. Int J Syst Evol Microbiol 50, 1315-1323.

McVeigh, H. P., Divers, M., Warwick, S., Munro, J. \& Embley, T. M. (1995). Exploration of Actinomycetes diversity using ribosomal RNA sequences. In Proceedings of the Ninth International Symposium on the Biology of the Actinomycetes, pp. 253-260. Edited by V. G. Debabov, Y. V. Dudnik \& V. N. Danilenko. Moscow.

Meyer, J. (1976). Genus Nocardiopsis, a new genus of the order Actinomycetales. Int J Syst Bacteriol 26, 487-493.

Miller, L. T. (1982). Single derivatization method for routine analysis of bacterial whole-cell fatty acid methyl esters, including hydroxy acids. $J$ Clin Microbiol 16, 584-586.

Morón, R., González, I. \& Genilloud, O. (1999). New genus-specific primers for the PCR identification of members of the genera Pseudonocardia and Saccharopolyspora. Int J Syst Bacteriol 49, 149-162.

Peltola, J., Andersson, M. A., Kämpfer, P., Auling, G., Kroppenstedt, R. M., Busse, H.-J., Salkinoja-Salonen, M. S. \& Rainey, F. A. (2001). Isolation of toxicogenic Nocardiopsis strains from indoor environments and description of two new Nocardiopsis species, $N$. exhalans sp. nov. and N. umidischolae sp. nov. Appl Environ Microbiol 67, 4293-4304.

Pernodet, J.-L., Boccard, F., Alegre, M.-T., Gagnat, J. \& Guerineau, M. (1989). Organization and nucleotide sequence analysis of a ribosomal RNA gene cluster from Streptomyces ambofaciens. Gene 79, 33-46.

Poschner, J., Kroppenstedt, R. M., Fischer, A. \& Stackebrandt, E. (1985). DNA-DNA reassociation and chemotaxonomic studies on
Actinomadura, Microbispora, Microtetraspora, Micropolyspora and Nocardiopsis. Syst Appl Microbiol 6, 264-270.

Rainey, F. A., Ward-Rainey, N., Kroppenstedt, R. M. \& Stackebrandt, E. (1996). The genus Nocardiopsis represents a phylogenetically coherent taxon and a distinct actinomycete lineage: proposal of Nocardiopsaceae fam. nov. Int J Syst Bacteriol 46, 1088-1092.

Salazar, O., Morón, R. \& Genilloud, O. (2000). New genus-specific primers for the PCR identification of the genus Saccharomonospora and evaluation of the microbial diversity of wild-type isolates of Saccharomonospora detected from soil DNAs. Int J Syst Evol Microbiol 50, 2043-2055

Stahl, D. A. \& Amann, R. (1991). Development and application of nucleic acid probes. In Nucleic Acid Techniques in Bacterial Systematics, pp. 205-248. Edited by E. Stackebrandt \& M. Goodfellow. Chichester: Wiley.

Swofford, D. L. (1993). PAUP: Phylogenetic analysis using parsimony, version 3.1.1. Washington, DC: Laboratory of Molecular Systematics, Smithsonian Institute.

Thompson, J. D., Higgins, D. G. \& Gibson, T. J. (1994). CLUSTAL W: improving the sensitivity of progressive multiple sequence alignment through sequence weighting, position-specific gap penalties and weight matrix choice. Nucleic Acids Res 22, 4673-4680.

Warwick, S., Bowen, T., McVeigh, H. \& Embley, T. M. (1994). A phylogenetic analysis of the family Pseudonocardiaceae and the genera Actinokineospora and Saccharothrix with 16S rRNA sequences and a proposal to combine the genera Amycolata and Pseudonocardia in an emended genus Pseudonocardia. Int J Syst Bacteriol 44, 293-299.

Yassin, A. F., Galinski, E. A., Wohlfarth, A., Jahnke, K.-D., Schaal, K. P. \& Trüper, H. G. (1993). A new actinomycete species, Nocardiopsis lucentensis sp. nov. Int J Syst Bacteriol 43, 266-271.

Yassin, A. F., Rainey, F. A., Burghardt, J., Gierth, D., Ungerechts, J., Lux, I., Seifert, P., Bal, C. \& Schaal, K. P. (1997). Description of Nocardiopsis synnemataformans sp. nov., elevation of Nocardiopsis alba subsp. prasina to Nocardiopsis prasina comb. nov., and designation of Nocardiopsis antarctica and Nocardiopsis alborubida as later subjective synonyms of Nocardiopsis dassonvillei. Int J Syst Bacteriol 47, 983-988. 